\title{
Effect of Feed Substrate Thickness on the Bandwidth and Radiation Characteristics of an Aperture-Coupled Micro- strip Antenna with a High Permittivity Feed Substrate
}

\author{
Jae-Hyun Kim·Boo-Gyoun Kim*
}

\begin{abstract}
The impedance bandwidth and radiation characteristics of an aperture-coupled microstrip line-fed patch antenna (ACMPA) with a high permittivity $\left(\varepsilon_{r}=10\right)$ feed substrate suitable for integration with a monolithic microwave integrated circuit (MMIC) are investigated for various feed substrate thicknesses through an experiment and computer simulation. The impedance bandwidth of an ACMPA with a high permittivity feed substrate increases as the feed substrate thickness decreases. Furthermore, the front-to-back ratio of an ACMPA with a high permittivity feed substrate increases and the cross-polarization level decreases as the feed substrate thickness decreases. As the impedance bandwidth of an ACMPA with a high permittivity feed substrate increases and its radiation characteristics improve as the feed substrate thickness decreases, the ACMPA configuration becomes suitable for integration with an MMIC.
\end{abstract}

Key Words: Aperture-Coupled Antenna, High Permittivity Feed Substrate, Monolithic Microwave Integrated Circuits (MMICs), Microstrip Antennas, Mutual Resonance.

\section{INTRODUCTION}

The antenna used for a next-generation base station antenna and radar is expected to be an active array antenna structure in which active amplifiers are mounted on each antenna element. Therefore, if an antenna is integrated into the front-end of a radio frequency module, the active array antenna structure will be simplified and its manufacturing cost will be reduced [1]. Microstrip patch antennas are used for many applications because of their many advantageous features, such as low profile, light weight, conformability, low fabrication cost, and suitability for integration with monolithic microwave integrated circuits (MMICs) [2].

MMICs are manufactured using high permittivity $\left(\varepsilon_{r}>10\right)$ materials, such as $\mathrm{Si}$ or GaAs. Therefore, antennas suitable for integration with MMICs should be designed on a high permittivity feed substrate. Many works have been conducted to develop antennas on a high permittivity feed substrate suitable for integration with an MMIC using various feeding methods [38].

An aperture-coupled microstrip line-fed patch antenna (ACMPA) can use two different dielectric substrates separated by a common ground plane. Therefore, an ACMPA with a low permittivity antenna substrate can be designed on a high permittivity feed substrate. This configuration of an ACMPA is particularly useful compared with other feeding methods when integrating an antenna with an MMIC. The impedance bandwidth of an ACMPA with a high permittivity feed substrate is

Manuscript received December 13, 2017 ; Revised January 25, 2018 ; Accepted February 21, 2018. (ID No. 20171213-075J)

School of Electronic Engineering, Soongsil University, Seoul, Korea.

"Corresponding Author: Boo-Gyoun Kim (e-mail: bgkim0325@ssu.ac.kr)

This is an Open-Access article distributed under the terms of the Creative Commons Attribution Non-Commercial License (http://creativecommons.org/licenses/by-nc/4.0) which permits unrestricted non-commercial use, distribution, and reproduction in any medium, provided the original work is properly cited.

(c) Copyright The Korean Institute of Electromagnetic Engineering and Science. All Rights Reserved. 
usually smaller than that of an ACMPA with a low permittivity feed substrate [3]. When a patch antenna is integrated with an MMIC, the feed substrate thickness of the patch antenna must be thin to reduce the manufacturing cost and facilitate integration [3].

The effects of altering the parameters of the feed substrate on the impedance bandwidth and radiation characteristics of a microstrip line-fed aperture stacked patch antenna (ASPA) with a high permittivity feed substrate have been theoretically investigated to determine the suitability of the ASPA for integration with an MMIC [3]. The structure of an ASPA is composed of two patches mutually coupled to an aperture to obtain a large impedance bandwidth. In this study, the impedance bandwidth of the ASPA decreases as the thickness of the feed substrate decreases when the ASPA has a feed substrate permittivity of 10.2, which is suitable for integration with an MMIC. The ASPA structure has been shown to be unsuitable for integration with MMICs [3].

In the current study, we investigate the effect of the feed substrate thickness of an ACMPA with a high permittivity $\left(\varepsilon_{r}=10\right)$ feed substrate suitable for integration with an MMIC on the impedance bandwidth and radiation characteristics of the ACMPA through an experiment and computer simulation. HighFrequency Structure Simulator (HFSS) is used for the simulations in this work. We show that the impedance bandwidth of an ACMPA with a high permittivity feed substrate increases and that its radiation characteristics improve as the thickness of the feed substrate decreases.

This paper is organized as follows. In Section II, an ACMPA with a high permittivity feed substrate is designed for using a mutual resonance produced by the interaction of an aperture with a patch to obtain a large impedance bandwidth. The effect of the feed substrate thickness of the ACMPA on the impedance bandwidth and input impedance characteristics is investigated through a computer simulation. In Section III, the simulated and measured results of the impedance bandwidth and radiation characteristics of the ACMPAs with various feed substrate thicknesses are presented. Section IV concludes the paper.

\section{INPUT IMPEDANCE CHARACTERISTICS OF AN}

\section{ACMPA VERSUS FEED SUBSTRATE THICKNESS}

Fig. 1 shows the schematic diagram of an ACMPA. The antenna consists of two substrates separated by a common ground plane. The radiating microstrip patch element is etched on the top of the antenna substrate, and the microstrip feed line is etched on the bottom of the feed substrate. A rectangular aperture with dimensions of $L_{a p} \times W_{a p}$ is etched on the ground plane, and it is designed for using a mutual resonance produced by the interaction between the aperture and the patch to obtain a large impedance bandwidth. The dimensions of the patch are $L_{p} \times W_{p}$. The relative permittivity and thickness of the feed (antenna) substrate are denoted as $\varepsilon_{r 1}\left(\varepsilon_{r 2}\right)$ and $h_{1}\left(h_{2}\right)$, respectively. The feed substrate selected in this study is a Taconic CER-10 substrate with a relative permittivity of 10 (similar to that of high permittivity materials commonly used in MMIC fabrication) and a loss tangent of 0.0035 . The antenna substrate selected in this study is a 3.2-mm-thick Taconic TLY-5 substrate $\left(\varepsilon_{r}=2.2, \tan \delta=0.0009\right)$. The microstrip line has a width of $w_{f}$ and an open-circuited stub length of $\ell_{s}$, and it is designed to have a characteristic impedance of $50 \Omega$.

To investigate the effect of the feed substrate thickness on the impedance bandwidth of the ACMPA with $W_{a p} / L_{a p}=1 / 10$ [8], four ACMPAs are designed with different feed substrate thicknesses. Table 1 shows the design parameters of the four ACMPAs with the different feed substrate thicknesses required to obtain the maximum impedance bandwidth at a center frequency of $10 \mathrm{GHz}$.

Fig. 2(a) and (b) show the simulated return loss and real part of the normalized input impedance versus frequency, respectively, of the four ACMPAs, with the design parameters shown in Table 1. In Fig. 2(a), the $10 \mathrm{~dB}$ return loss bandwidths of the ACMPAs with $h_{1}=0.10 \mathrm{~mm}, 0.28 \mathrm{~mm}, 0.78 \mathrm{~mm}$, and 1.58 $\mathrm{mm}$ are $30.6 \%$ (8.49-11.56 GHz), $27.8 \%(8.66-11.46 \mathrm{GHz})$, $22.1 \%(8.88-11.09 \mathrm{GHz})$, and $18.1 \%(9.11-10.92 \mathrm{GHz})$, respectively. Fig. 2(a) shows that the $10 \mathrm{~dB}$ return loss bandwidth

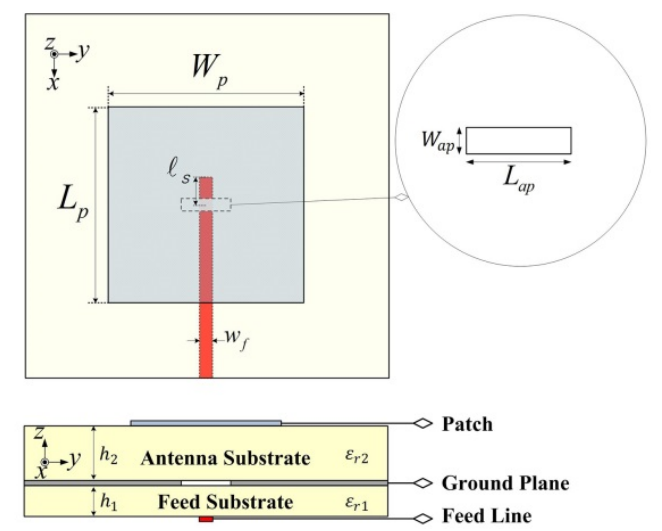

Fig. 1. Geometry of an ACMPA.

Table 1. Design parameters of the four ACMPAs with different feed substrate thicknesses

\begin{tabular}{cccccccc}
\hline Model & $\begin{array}{c}h_{1} \\
(\mathrm{~mm})\end{array}$ & $\varepsilon_{r 1}$ & $\begin{array}{c}L_{p} \\
(\mathrm{~mm})\end{array}$ & $\begin{array}{c}L_{a p} \\
(\mathrm{~mm})\end{array}$ & $\begin{array}{c}W_{a p} \\
(\mathrm{~mm})\end{array}$ & $\begin{array}{c}\ell_{s} \\
(\mathrm{~mm})\end{array}$ & $\begin{array}{c}w_{f} \\
(\mathrm{~mm})\end{array}$ \\
\hline $\mathrm{A}$ & 0.10 & & & 7.0 & 0.70 & 0.88 & 0.11 \\
$\mathrm{~B}$ & 0.28 & \multirow{2}{*}{10} & 7.2 & 6.5 & 0.65 & 0.80 & 0.32 \\
$\mathrm{C}$ & 0.78 & & & 5.8 & 0.58 & 0.79 & 0.79 \\
$\mathrm{D}$ & 1.58 & & & 5.3 & 0.53 & 0.47 & 1.39 \\
\hline
\end{tabular}




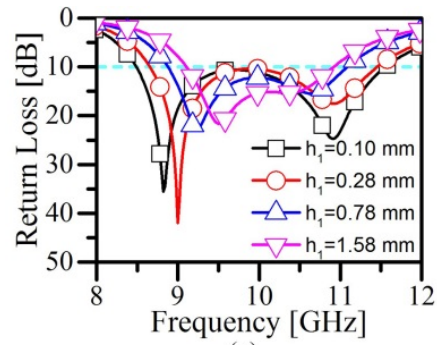

(a)

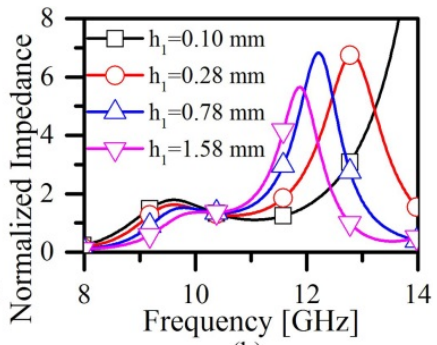

(b)
Fig. 2. (a) Return loss and (b) real part of the normalized input impedance versus frequency of the four ACMPAs, with the design parameters shown in Table 1.

decreases as the feed substrate thickness increases. This phenomenon can be explained by the input impedance characteristics of the ACMPAs according to the feed substrate thickness.

Fig. 2(b) shows the real part of the normalized input impedance versus frequency of the four ACMPAs with different feed substrate thicknesses. In this study, the resonance frequency of the ACMPA is defined as the frequency in which the real part of the impedance reaches maximum [9]. When the feed substrate thickness is $0.10 \mathrm{~mm}$, the resonance frequency of the aperture is about $14.22 \mathrm{GHz}$ and that of the patch is about 9.60 $\mathrm{GHz}$, so that the mutual resonance region between the two resonance frequencies is very large. When the feed substrate thickness is $0.28 \mathrm{~mm}(0.78 \mathrm{~mm})$, the resonance frequency of the aperture is about $12.82 \mathrm{GHz}(12.22 \mathrm{GHz})$ and that of the patch is about $9.62 \mathrm{GHz}(9.78 \mathrm{GHz})$. When the feed substrate thickness is $1.58 \mathrm{~mm}$, the resonance frequency of the aperture is about $11.88 \mathrm{GHz}$ and that of the patch is about $10.08 \mathrm{GHz}$, so that the mutual resonance region between the two resonance frequencies is small compared with those of the other three feed substrate thicknesses. As the feed substrate thickness decreases, the mutual resonance region between the two resonance frequencies increases. The reasons for this outcome are as follows.

As the feed substrate thickness decreases, the coupling strength between the feedline and the aperture [10] as well as the aperture length for the maximum impedance bandwidth of the ACMPA increase. Therefore, the coupling strength between the aperture and the patch resonance increases as the feed substrate thickness decreases. As the frequency range between the aperture and the patch resonances increases because of the increase in the mutual resonance strength [11], the impedance bandwidth of an ACMPA caused by the mutual resonance increases as the feed substrate thickness decreases.

\section{SIMULATION AND MEASUREMENT RESULT}

Fig. 3 shows photographs of the three fabricated ACMPAs with different feed substrate thicknesses. The dielectric constants of the commercially available Taconic CER-10 substrates used as feed substrates are measured as 8.8, 9.3, and 9.75 for the feed substrate thicknesses of $0.28 \mathrm{~mm}, 0.78 \mathrm{~mm}$, and $1.58 \mathrm{~mm}$, respectively. The antenna substrate used for the three fabricated ACMPAs shown in Fig. 3 is a 3.2-mm-thick Taconic TLY-5 substrate $\left(\varepsilon_{r}=2.2, \tan \delta=0.0009\right)$. Table 2 presents the design parameters of the fabricated ACMPAs required to obtain the maximum $10 \mathrm{~dB}$ return loss bandwidth at a center frequency of $10 \mathrm{GHz}$. As the feed substrate thickness decreases, the width of the $50 \Omega$ microstrip transmission line decreases, as shown in Table 2. If the width of the microstrip transmission line on a high permittivity feed substrate decreases, the insertion loss between the connector and the transmission line increases. Therefore, to minimize the insertion loss, different connectors are used for the three fabricated ACMPAs with different feed substrate thicknesses, as shown in Fig. 3. To compare the simulation results with the measurement results, the relative permittivity of the feed substrate obtained from the measurement is used in the simulation.

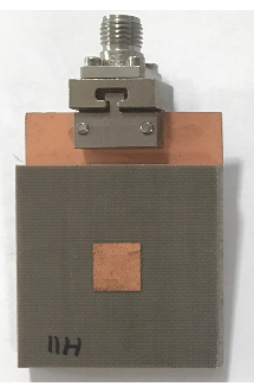

(a)

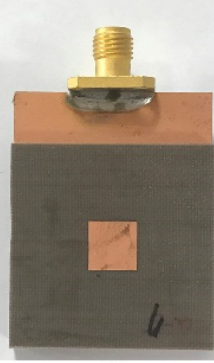

(b)

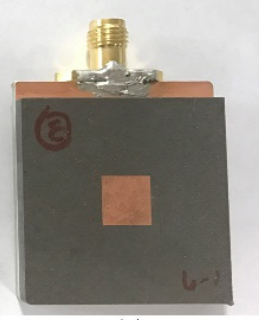

(c)
Fig. 3. Photographs of the three fabricated ACMPAs with different feed substrate thicknesses: (a) $h_{1}=0.28 \mathrm{~mm}$, (b) $h_{1}=$ $0.78 \mathrm{~mm}$, and (c) $h_{1}=1.58 \mathrm{~mm}$.

Table 2. Design parameters of the three ACMPAs with different feed substrate thicknesses

\begin{tabular}{lccccccc}
\hline Model & $\begin{array}{c}b_{1} \\
(\mathrm{~mm})\end{array}$ & $\varepsilon_{r 1}$ & $\begin{array}{c}L_{p} \\
(\mathrm{~mm})\end{array}$ & $\begin{array}{c}L_{a p} \\
(\mathrm{~mm})\end{array}$ & $\begin{array}{c}W_{a p} \\
(\mathrm{~mm})\end{array}$ & $\begin{array}{c}\ell_{s} \\
(\mathrm{~mm})\end{array}$ & $\begin{array}{c}w_{f} \\
(\mathrm{~mm})\end{array}$ \\
\hline $\mathrm{A}$ & 0.28 & 8.8 & & 6.3 & 0.63 & 0.80 & 0.31 \\
$\mathrm{~B}$ & 0.78 & 9.3 & 7.2 & 5.7 & 0.57 & 0.80 & 0.81 \\
$\mathrm{C}$ & 1.58 & 9.75 & & 5.4 & 0.54 & 0.45 & 1.41 \\
\hline
\end{tabular}

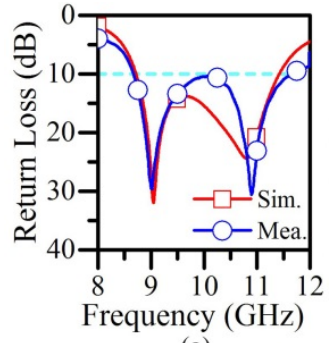

(a)

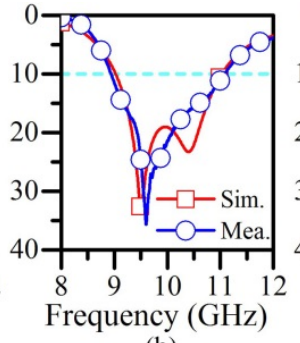

(b)

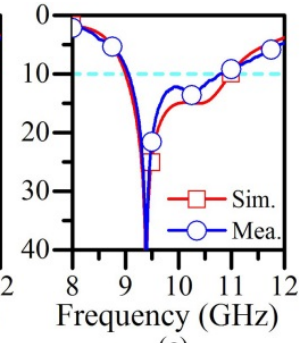

(c)
Fig. 4. Simulated and measured return losses of the three ACMPAs with different feed substrate thicknesses: (a) $h_{1}=0.28$ $\mathrm{mm},(\mathrm{b}) h_{1}=0.78 \mathrm{~mm}$, and (c) $h_{1}=1.58 \mathrm{~mm}$. 
Fig. 4(a)-(c) show the simulated and measured return losses of the fabricated ACMPAs (Fig. 3) with feed substrate thicknesses of $0.28 \mathrm{~mm}, 0.78 \mathrm{~mm}$, and $1.58 \mathrm{~mm}$, respectively. The measured results are in good agreement with the simulated results. The measured $10 \mathrm{~dB}$ return loss bandwidths of the ACMPAs with $h_{1}=0.28 \mathrm{~mm}, h_{1}=0.78 \mathrm{~mm}$, and $h_{1}=1.58 \mathrm{~mm}$ are $29.3 \%(8.67-11.65 \mathrm{GHz}), 21.3 \%(8.94-11.08 \mathrm{GHz})$, and $17.4 \%$ (9.06-10.79 GHz), respectively. As the feed substrate thickness decreases, the impedance bandwidth increases.

Fig. 5 shows the input impedance loci plotted on a Smith chart of ACMPAs with a high permittivity $\left(\varepsilon_{r}=10\right)$ feed substrate for various feed substrate thicknesses. The inner circle on the Smith chart corresponds to the voltage standing wave ratio (VSWR) of 2. The input impedance loci have a loop inside the inner circle because of mutual resonance. The frequency range of the ACMPAs with $h_{1}=0.28 \mathrm{~mm}, h_{1}=0.78 \mathrm{~mm}$, and $h_{1}=$ $1.58 \mathrm{~mm}$ located inside the inner circle, on which the VSWR is 2, are $8.67-11.65 \mathrm{GHz}, 8.94-11.08 \mathrm{GHz}$, and 9.06-10.79 $\mathrm{GHz}$, respectively. Therefore, the $10 \mathrm{~dB}$ return loss bandwidths of the ACMPAs with $h_{1}=0.28 \mathrm{~mm}, h_{1}=0.78 \mathrm{~mm}$, and $h_{1}=$

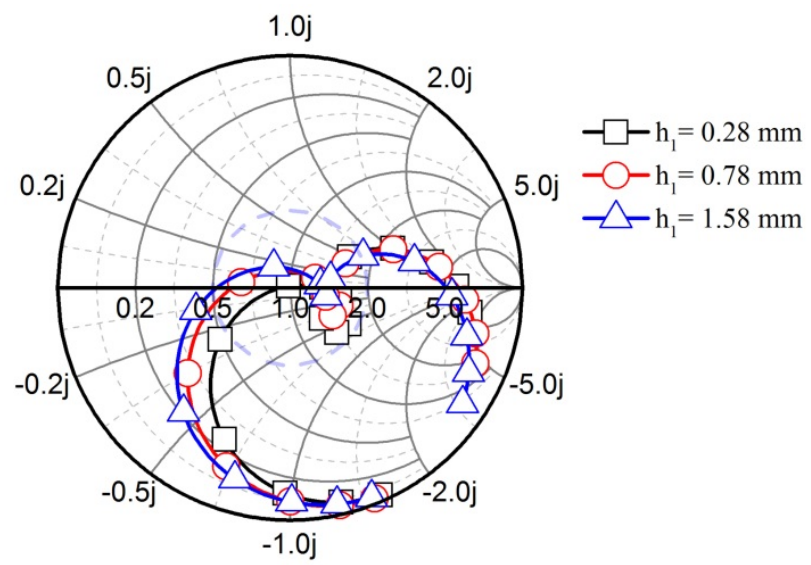

Fig. 5. Input impedance loci plotted on a Smith chart of ACMPAs with a high permittivity $\left(\varepsilon_{r}=10\right)$ feed substrate for various feed substrate thicknesses.
$1.58 \mathrm{~mm}$ are $29.3 \%, 21.3 \%$, and $17.4 \%$, respectively.

Fig. 6 shows the simulated and measured E-plane radiation patterns of the three ACMPAs with different feed substrate thicknesses at $10 \mathrm{GHz}$. In the case of the co-polarization patterns, the measured results are in good agreement with the simulated results. The simulated cross-polarization gains of ACMPAs with $h_{1}=0.28 \mathrm{~mm}, h_{1}=0.78 \mathrm{~mm}$, and $h_{1}=1.58 \mathrm{~mm}$ are $-38.42 \mathrm{dBi},-38.84 \mathrm{dBi}$, and $-29.80 \mathrm{dBi}$, respectively. When the feed substrate thickness is $1.58 \mathrm{~mm}$, the cross-polarization gain increases by about $10 \mathrm{~dB}$ compared with those of the other two cases. The measured results for the cross-polarization gains of the three ACMPAs with different feed substrate thicknesses show larger values than the simulated results because of the alignment error of the antenna with respect to the probe in the measurement process.

Fig. 7 shows the simulated and measured $\mathrm{H}$-plane radiation patterns of the three ACMPAs with different feed substrate thicknesses at $10 \mathrm{GHz}$. In the case of the co-polarization patterns, the measured results are in good agreement with the simulated results. The simulated cross-polarization gains of ACMPAs with $h_{1}=0.28 \mathrm{~mm}, h_{1}=0.78 \mathrm{~mm}$, and $h_{1}=1.58 \mathrm{~mm}$ are $-20.07 \mathrm{dBi},-7.15 \mathrm{dBi}$, and $-6.64 \mathrm{dBi}$, respectively. The measured cross-polarization gains slightly differ from those of the simulated results. The measured cross-polarization gain of the ACMPA with $h_{1}=0.28 \mathrm{~mm}$ is $-15.20 \mathrm{dBi}$, which is $5 \mathrm{~dB}$ less than those of the other two cases.

Table 3 shows the measured radiation characteristics of the three ACMPAs with different feed substrate thicknesses at three different frequencies. The minimum broadside gain of $4.96 \mathrm{dBi}$ is obtained at $11 \mathrm{GHz}$ when the feed substrate thickness is $1.58 \mathrm{~mm}$. The maximum broadside gain of $6.59 \mathrm{dBi}$ is obtained at $11 \mathrm{GHz}$ when the feed substrate thickness is 0.78 $\mathrm{mm}$. As the return loss varies depending on the substrate thickness and frequency, as shown in Fig. 4, the broadside gain also varies depending on the substrate thickness and frequency. The difference in the broadside gain according to the substrate

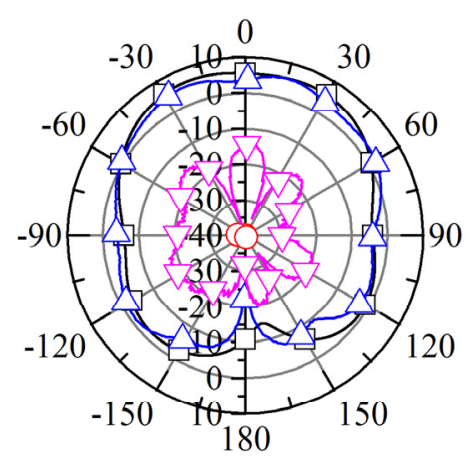

(a)

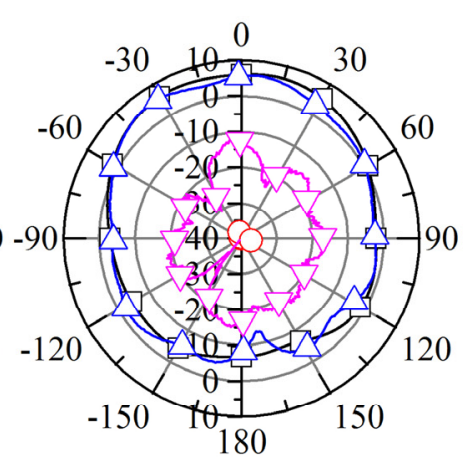

(b)

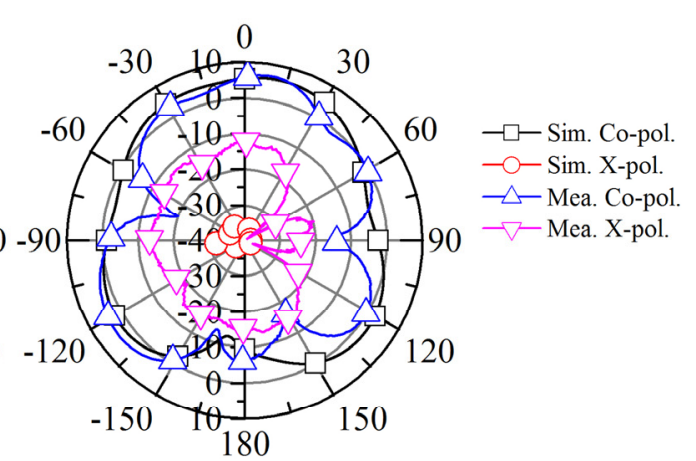

(c)

Fig. 6. Simulated and measured E-plane radiation patterns of the three ACMPAs with different feed substrate thicknesses at $10 \mathrm{GHz}$. (a) $h_{1}=0.28 \mathrm{~mm}$, (b) $h_{1}=0.78 \mathrm{~mm}$, and (c) $h_{1}=1.58 \mathrm{~mm}$. 


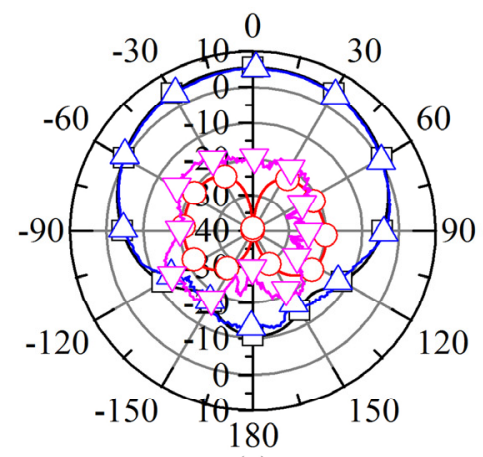

(a)

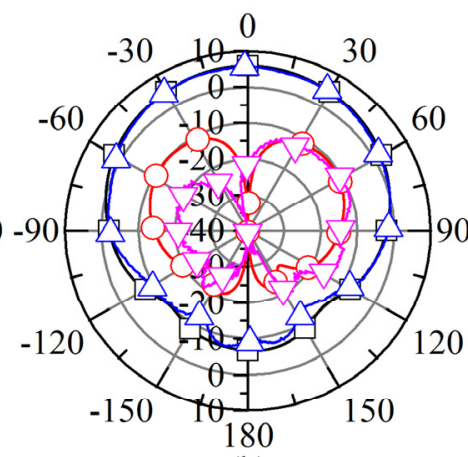

(b)

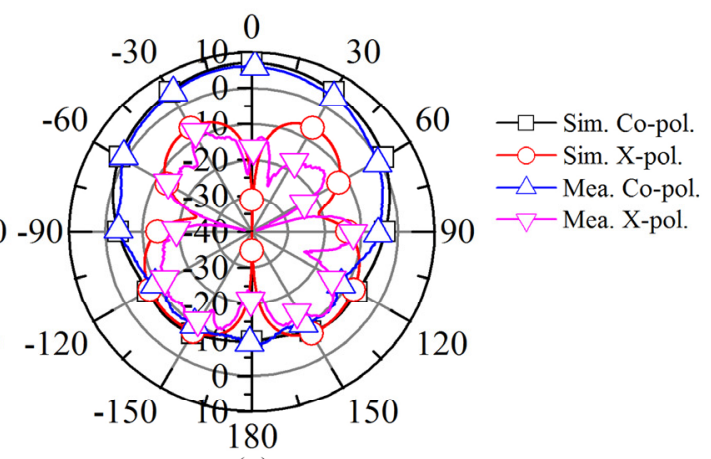

(c)

Fig. 7. Simulated and measured H-plane radiation patterns of the three ACMPAs with different feed substrate thicknesses at $10 \mathrm{GHz}$. (a) $h_{1}=0.28 \mathrm{~mm}$, (b) $h_{1}=0.78 \mathrm{~mm}$, and (c) $h_{1}=1.58 \mathrm{~mm}$.

thickness is not significant.

The front-to-back ratio (FBR) of the E-plane increases at 9 $\mathrm{GHz}$ and $10 \mathrm{GHz}$ as the feed substrate thickness decreases. At $11 \mathrm{GHz}$, the FBR of the ACMPA with the largest feed substrate thickness $\left(h_{1}=1.58 \mathrm{~mm}\right)$ has the highest FBR of $9.69 \mathrm{~dB}$. However, the FBRs of the other two ACMPAs are only 1.37 $\mathrm{dB}$ less than that of the ACMPA with the largest feed substrate thickness. The ACMPA with the smallest feed substrate thickness $\left(h_{1}=0.28 \mathrm{~mm}\right)$ has the highest FBR of the H-plane of $18.08 \mathrm{~dB}$ and $13.84 \mathrm{~dB}$ at $10 \mathrm{GHz}$ and $11 \mathrm{GHz}$, respectively. At $9 \mathrm{GHz}$, the ACMPA with a feed substrate thickness of 0.78 $\mathrm{mm}$ has the highest FBR of $12.06 \mathrm{~dB}$, which is only $1.38 \mathrm{~dB}$ larger than that of the ACMPA with the smallest feed substrate thickness. The FBR in this work is defined as the ratio of the broadside gain to the maximum value of all backlobes within a cone of $\pm 30^{\circ}$ around the negative $\mathrm{z}$-axis with respect to the forward radiation [12].

As the feed substrate thickness decreases, the cross-polarization level of the $\mathrm{H}$-plane decreases for all frequencies. The cross-polarization level of the E-plane also decreases at $9 \mathrm{GHz}$ and $10 \mathrm{GHz}$ as the feed substrate thickness decreases. At 11 $\mathrm{GHz}$, the cross-polarization level of the E-plane of the ACMPA with the smallest feed substrate thickness $\left(h_{1}=0.28 \mathrm{~mm}\right)$ is $-20.89 \mathrm{~dB}$, which is $4.22 \mathrm{~dB}$ larger than that of the ACMPA with $h_{1}=1.58 \mathrm{~mm}$. However, the simulated cross-polarization level of the E-plane of the ACMPA with $h_{1}=0.28 \mathrm{~mm}$ is $-40.97 \mathrm{~dB}$ at $11 \mathrm{GHz}$, which is $1.39 \mathrm{~dB}$ less than that of the ACMPA with $h_{1}=1.58 \mathrm{~mm}$. The measurement error is considered to have caused that the measured cross-polarization level of the E-plane of the ACMPA with $h_{1}=0.28 \mathrm{~mm}$ to be larger

Table 3. Measured radiation characteristics of the three ACMPAs with different feed substrate thicknesses at $9 \mathrm{GHz}, 10 \mathrm{GHz}$, and 11 $\mathrm{GHz}$

\begin{tabular}{|c|c|c|c|c|c|c|c|c|c|c|c|}
\hline \multirow{2}{*}{ Model } & \multirow{2}{*}{$\begin{array}{c}b_{1} \\
(\mathrm{~mm})\end{array}$} & \multirow{2}{*}{$\begin{array}{l}\text { Observation } \\
\text { plane }\end{array}$} & \multicolumn{3}{|c|}{ Broadside gain ( $\mathrm{dBi}$ ) } & \multicolumn{3}{|c|}{ Front-to-back ratio (dB) } & \multicolumn{3}{|c|}{ Cross-pol. level (dB) } \\
\hline & & & $9 \mathrm{GHz}$ & $10 \mathrm{GHz}$ & $11 \mathrm{GHz}$ & $9 \mathrm{GHz}$ & $10 \mathrm{GHz}$ & $11 \mathrm{GHz}$ & $9 \mathrm{GHz}$ & $10 \mathrm{GHz}$ & $11 \mathrm{GHz}$ \\
\hline \multirow{2}{*}{ A } & \multirow{2}{*}{0.28} & E-plane & \multirow{2}{*}{5.72} & \multirow{2}{*}{5.07} & \multirow{2}{*}{5.94} & 8.56 & 11.05 & 8.37 & -24.09 & -19.56 & -20.89 \\
\hline & & H-plane & & & & 10.64 & 18.08 & 13.84 & -23.69 & -20.27 & -19.89 \\
\hline \multirow{2}{*}{ B } & \multirow{2}{*}{0.78} & E-plane & \multirow{2}{*}{5.09} & \multirow{2}{*}{5.72} & \multirow{2}{*}{6.59} & 4.22 & 9.74 & 8.32 & -20.24 & -17.67 & -19.21 \\
\hline & & H-plane & & & & 12.06 & 13.10 & 9.83 & -17.41 & -16.00 & -16.97 \\
\hline \multirow{2}{*}{$\mathrm{C}$} & \multirow{2}{*}{1.58} & E-plane & \multirow{2}{*}{5.38} & \multirow{2}{*}{5.49} & \multirow{2}{*}{4.96} & 4.18 & 5.81 & 9.69 & -17.66 & -17.79 & -25.11 \\
\hline & & H-plane & & & & 4.60 & 14.85 & 6.78 & -13.80 & -15.70 & -12.26 \\
\hline
\end{tabular}

Table 4. Small FBRs and large cross-polarization levels of the three ACMPAs with different feed substrate thicknesses at $9 \mathrm{GHz}, 10 \mathrm{GHz}$, and $11 \mathrm{GHz}$

\begin{tabular}{|c|c|c|c|c|c|c|c|}
\hline \multirow{2}{*}{ Model } & \multirow{2}{*}{$h_{1}(\mathrm{~mm})$} & \multicolumn{3}{|c|}{ Front-to-back ratio $(\mathrm{dB})$} & \multicolumn{3}{|c|}{ Cross-pol. level (dB) } \\
\hline & & $9 \mathrm{GHz}$ & $10 \mathrm{GHz}$ & $11 \mathrm{GHz}$ & $9 \mathrm{GHz}$ & $10 \mathrm{GHz}$ & $11 \mathrm{GHz}$ \\
\hline $\mathrm{A}$ & 0.28 & 8.56 & 11.05 & 8.37 & -23.69 & -19.56 & -19.89 \\
\hline B & 0.78 & 4.22 & 9.74 & 8.32 & -17.41 & -16.00 & -16.97 \\
\hline $\mathrm{C}$ & 1.58 & 4.18 & 5.81 & 6.78 & -13.80 & -15.70 & -12.26 \\
\hline
\end{tabular}


than that of the ACMPA with $h_{1}=1.58 \mathrm{~mm}$. The crosspolarization level in this work is defined as the maximum crosspolarization in the broadside relative to the maximum $\mathrm{co}^{-}$ polarized field [13]. Moreover, the broadside gain is hardly affected by the feed substrate thickness.

The antenna performance is determined by a small FBR and a large cross-polarization level regardless of the E-plane and the $\mathrm{H}$-plane. Table 4 shows the measured small FBRs and the large cross-polarization levels of the three ACMPAs at three different frequencies. As indicated in the table, as the feed substrate thickness decreases, the FBR increases and the cross-polarization level decreases. However, this tendency may not be exactly shown because of the measurement error when the measured FBRs and cross-polarization levels of the three ACMPAs at three different frequencies are compared in each plane.

\section{CONCLUSION}

The radiation characteristics and impedance bandwidth of an ACMPA with a high permittivity $\left(\varepsilon_{r}=10\right)$ feed substrate suitable for integration with an MMIC are investigated through an experiment and computer simulation for various feed substrate thicknesses. The impedance bandwidth of an ACMPA with a high permittivity feed substrate increases as the feed substrate decreases. Furthermore, as the feed substrate thickness decreases, the FBR increases and the cross-polarization level decreases. The broadside gain is hardly affected by the feed substrate thickness.

This research was supported by the Basic Science Research Program through the National Research Foundation of Korea (NRF) funded by the Ministry of Education (No. NRF-2015R1D1A1A01059745).

\section{REFERENCES}

[1] Z. N. Chen and K. M. Luk, Antennas for Base Stations in Wireless Communications. New York, NY: McGraw-Hill, 2009.

[2] R. Garg, P. Bhartia, I. Bahl, and A. Ittipiboon, Microstrip Antenna Design Handbook. Boston, MA: Artech House, 2001.
[3] W. S. T. Rowe and R. B. Waterhouse, "Theoretical investigation on the use of high permittivity materials in microstrip aperture stacked patch antennas," IEEE Transactions on Antennas and Propagation, vol. 51, no. 9, pp. 2484-2486, 2003.

[4] R. B. Waterhouse and W. S. T. Rowe, "MMIC compatible printed antennas," Electronics Letters, vol. 39, no. 21, pp. 1493-1495, 2003.

[5] R. B. Waterhouse, "Stacked patches using high and low dielectric constant material combinations," IEEE Transactions on Antennas and Propagation, vol. 47, no. 12, pp. 1767$1771,1999$.

[6] K. Hettak, G. Delisle, and M. Boulmalf, "A novel integrated antenna for millimeter-wave personal communication systems," IEEE Transactions on Antennas and Propagation, vol. 46, no. 11, pp. 1757-1758, 1998.

[7] E. Herth, N. Rolland, and T. Larsi, "Circularly polarized millimeter-wave antenna using 0-level packaging," IEEE Antennas and Wireless Propagation Letters, vol. 9, pp. 934937, 2010.

[8] D. M. Pozar, "A review of aperture coupled microstrip antenna: history, operation, development, and applications," 1996 [Online]. Available: http://www.ecs.umass.edu/ece/ pozar/aperture.pdf.

[9] A. Lai, K. M. K. H. Leong, and T. Itoh, "Infinite wavelength resonant antennas with monopolar radiation pattern based on periodic structures," IEEE Transactions on Antennas and Propagation, vol. 55, no. 3, pp. 868-876, 2007.

[10] L. Liu, E. Korolkiewicz, Z. Ghassemlooy, A. Sambell, S. Danaher, and K. Busawon, "Investigation of the equivalent circuit parameters and design of a dual polarized dual frequency aperture coupled microstrip antenna," IEEE Transactions on Antennas and Propagation, vol. 61, no. 4, pp. 23042308, 2013.

[11] S. L. Chuang, Physics of Optoelectronic Devices. New York, NY: John Wiley \& Sons, 1995, pp. 288-294.

[12] Y. X. Guo, K. M. Luk, and K. F. Lee, "L-probe fed thicksubstrate patch antenna mounted on a finite ground plane," IEEE Transactions on Antennas and Propagation, vol. 51, no. 8, pp. 1955-1963, 2003.

[13] S. Bhardwaj and Y. Rahmat-Samii, "Revisiting the generation of cross-polarization in rectangular patch antennas: a near-field approach," IEEE Antennas and Propagation Magazine, vol.56, no. 1, pp.14-38, 2014. 


\section{Jae-Hyun Kim}

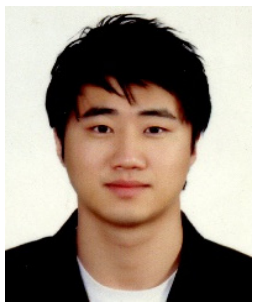

received his B.S. and M.S. degrees in electronic engineering from Soongsil University, Seoul, Korea, in 2012 and 2014, respectively. He is currently pursuing his Ph.D. degree. His main research interests are patch antennas, phased array antennas, and metamaterial.

\section{Boo-Gyoun Kim}

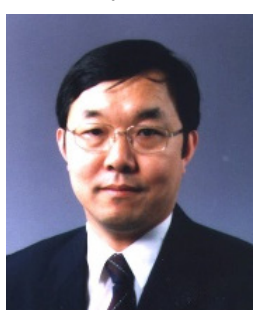

received his B.S. degree in electronic engineering from Seoul National University, Seoul, Korea, in 1979, his M.S. degree in electronic engineering from the Korea Advanced Institute of Science and Technology, Seoul, Korea, in 1981, and his Ph.D. degree in electrical engineering from the University of

Southern California, Los Angeles, USA, in 1989. In 1981, he joined the School of Electronic Engineering, Soongsil University in Seoul, where he is now a professor. He was the dean of the College of Information Technology of Soongsil University from March 2008 to February 2010. His main research interests are patch antennas, electromagnetic bandgap structures, and phased array antennas. 